Article

\title{
Coastal Flooding Risk Assessment Using a GIS-Based Spatial Multi-Criteria Decision Analysis Approach
}

\author{
Vahid Hadipour ${ }^{1, *}$, Freydoon Vafaie ${ }^{1}$ and Kaveh Deilami ${ }^{2}$ (I) \\ 1 Department of Environmental Engineering, Faculty of Civil Engineering, K.N.Toosi University of \\ Technology, Tehran 19967-15433, Iran; fvafai@kntu.ac.ir \\ 2 Centre for Urban Research, School of Global, Urban and Social Studies, RMIT University, GPO Box 2476, \\ Melbourne, VIC 3001, Australia; kaveh.deilami@rmit.edu.au \\ * Correspondence: vhadipour@mail.kntu.ac.ir
}

Received: 10 July 2020; Accepted: 20 August 2020; Published: 25 August 2020

\begin{abstract}
Coastal areas are expected to be at a higher risk of flooding when climate change-induced sea-level rise (SLR) is combined with episodic rises in sea level. Flood susceptibility mapping (FSM), mostly based on statistical and machine learning methods, has been widely employed to mitigate flood risk; however, they neglect exposure and vulnerability assessment as the key components of flood risk. Flood risk assessment is often conducted by quantitative methods (e.g., probabilistic). Such assessment uses analytical and empirical techniques to construct the physical vulnerability curves of elements at risk, but the role of people's capacity, depending on social vulnerability, remains limited. To address this gap, this study developed a semiquantitative method, based on the spatial multi-criteria decision analysis (SMCDA). The model combines two representative concentration pathway (RCP) scenarios: RCP 2.6 and RCP 8.5, and factors triggering coastal flooding in Bandar Abbas, Iran. It also employs an analytical hierarchy process (AHP) model to weight indicators of hazard, exposure, and social vulnerability components. Under the most extreme flooding scenario, $14.8 \%$ of flooded areas were identified as high and very high risk, mostly located in eastern, western, and partly in the middle of the City. The results of this study can be employed by decision-makers to apply appropriate risk reduction strategies in high-risk flooding zones.
\end{abstract}

Keywords: SLR; coastal flooding; flood risk; social vulnerability; flood hazard; exposure; AHP; RCP scenarios

\section{Introduction}

Coastal cities, as an intersection of land and sea, play a crucial role in the national and global economy, particularly in developing countries. In 2070, the total value of assets (the world's large port cities) exposed to coastal flooding (100 year return periods) is projected to increase more than ten times compared with the year 2005 ( 3 trillion US dollars) [1]. The number of residents living in low-elevation coastal zones (areas less than $10 \mathrm{~m}$ above mean sea level) has also been growing, and this trend is estimated to continue faster than in inland areas [2]. Similarly, the population of major ports exposed to 100 year coastal floods is predicted to increase due to socioeconomic development in the coming decades [1-3].

According to the fifth assessment report of the Intergovernmental Panel on Climate Change (IPCC), by 2100, the coastal cities will experience both sea-level rise (ranging from $0.28 \mathrm{~m}$ to $0.98 \mathrm{~m}$ ) and much more intense storm surges [4]. Such storm flooding occasionally causes significant physical damages, loss of life, and economic losses. Examples of such incidents include Hurricane Katrina (2005), Hurricane Sandy (2012), and Typhoon Haiyan (2014) [5-7]. Flood risk is defined as the product of hazard: the chance of flood occurrence; exposure: the subjected population and value of properties 
to flooding; and vulnerability: the susceptibility of the exposed elements to the hazard [8,9]. In this context, coastal flooding risk assessment as a vital factor in flood management is essential. It helps urban planners and policymakers to design effective strategies in reducing the risk of flood-prone areas [10].

Over the past years, many studies have employed various statistical and machine learning methods to improve flood susceptibility mapping (FSM). Examples of these methods include frequency ratio [11], weight of evidence [12], analytical hierarchy process (AHP) [13,14], logistic regression [15], multiple criteria decision [16], fuzzy weight of evidence [17], artificial neural networks [18], support vector machine [19], decision tree [20], random forest [21], and ensembles models [22]. The FSM methods deal with flood conditioning factors (e.g., rainfall, slope, elevation, distance to a river, curvature, drainage density, flow accumulation, land use/cover, geology, surface runoff, and soil) to identify flood hazard in a given area [17]. The mentioned studies have focused on a flood hazard assessment that can support decision-makers to apply appropriate mitigation measures. However, a comprehensive flood risk management should consider the other risk components, that is, vulnerability and exposure, which are ignored in such studies. As another limitation, most of these methods identify flooded areas without considering flooding depth to assess the FSM.

Vulnerability, compared with exposure and hazard components, has received less attention in assessing flood risk [23]. Vulnerability concept varies among different communities [8,24-26], but there are two main perspectives on this [27]: (i) engineering and natural science, and (ii) social science. From the engineering and natural science viewpoint, vulnerability is defined as the susceptibility of exposed elements (e.g., assets, people) to flood hazards [8,28]. In this sense, vulnerability is often limited to a physical vulnerability where the vulnerability of structures and assets is estimated based on a given flood depth. In other words, the degree of damage is estimated using quantitative methods, mostly based on the depth-damage functions (vulnerability curves), ranging from zero (no damage) to one (total damage) [29]. Nevertheless, in reality, the vulnerability has a broader meaning in flooding, and capturing the vulnerability of residents remains limited in such studies [29-31]. From the social scientists' perspective, the vulnerability can be identified as an inherent characteristic of the system (people or community) before encountering the external hazard event [32-34]. To implement adaptation strategies aimed at flood risk reduction, the household capacity to respond to hazards is essential as much as the property's susceptibility [31]. The sociodemographic characteristics of households determine this capacity [25] and reveal how various social groups and communities act differently to the same flooding hazard $[35,36]$. However, to date, a few attempts have been made to link social vulnerability into hazard and exposure components to assess flood risk [31,37-39].

Unlike quantitative methods, semiquantitative methods combine indicators in a simplified way to build a flood risk index [40]. To implement semiquantitative methods, spatial multi-criteria decision analysis (SMCDA), generally based on the AHP model [41], can be employed. It can be easily linked to Geographic Information System (GIS) for further geospatial analysis. The GIS-based SMCDA approach can solve complex decisions by breaking those into a hierarchical form, identifying the relative importance of criteria, and incorporating them in an organized way [42]. In the context of flood risk, many studies have adopted the AHP model to evaluate the risk of river or flash flooding [43-50]. However, the application of the AHP in coastal flooding risk analysis is still rare [51-53], where the flood risk can be evaluated in a nonmonetary value. In the conducted studies related to coastal flooding hazards, most scholars paid particular attention to sea-level rise (SLR) and storm surges. To the best of our knowledge, a few studies combined these factors with the other episodic rises in sea level such as tide, wind set-up, that is, the vertical rise in mean water level caused by wind stresses on the water surface, and wave set-up, that is, a rise in mean water level due to wave breaking [54].

In Iran, to date, a few studies have been carried out on vulnerability and risk assessment of coastal cities exposed to SLR and flooding [35], and there is still a lack of studies on holistic coastal flooding risk assessments at local scales. Given the above concerns, the main objective of this study is to assess flood risk due to SLR and coastal flooding in Bandar Abbas City, the largest port city in the south 
of Iran. For this purpose, a GIS-based SMCDA approach, based on the AHP model, is developed to build a risk index due to coastal flooding, and map it by integrating three key risk components, that is, flood hazard, social vulnerability, and exposure. This study is distinct from previous studies as it provides three significant policy implications for urban planners and policymakers: (i) identifying flood hazard areas under future flooding scenarios, in 2050 and 2100, resulting from a combination of climate change-induced SLR and other coastal flooding triggers, that is, storm surge, high tide, wave set-up, and wind set-up, (ii) building a social vulnerability index using a set of sociodemographic indicators, and combining it with hazard and exposure components to build a flood risk index; and (iii) providing a rapid flood risk assessment approach which gives insights to the coastal planner and decision-makers for better planning in the future.

\section{Study Area}

Bandar Abbas City, the capital of Hormozgan province, is located on the Iranian south coast $\left(27^{\circ} 9^{\prime} \mathrm{N}-27^{\circ} 15^{\prime} \mathrm{N}\right.$ and $\left.56^{\circ} 12^{\prime} \mathrm{E}-56^{\circ} 24^{\prime} \mathrm{E}\right)$. Geographically it is surrounded by the Persian Gulf from the south (Figure 1). The total population of Bandar Abbas City was around 520,000 (2012), and its population growth has been increasing by nearly $2.3 \%$ per year [55]. Approximately $17 \%$ of the City has an elevation of less than $5 \mathrm{~m}$ [35], mostly located in the southwest, southeast with elevation ranging from 0.6 to $5 \mathrm{~m}$ higher than sea level [56]. The mean annual precipitation in Bandar Abbas is $200 \mathrm{~mm}$. The temperature varies from 2 to 44 Celsius during the coldest and hottest of the year, respectively. Summer continues for almost nine months in this city [56]. Bandar Abbas's urban area is around $40 \mathrm{~km}^{2}$ and is divided into three administrative districts. As the largest port city in Iran, it plays a significant role in the local and national economy. Over the past decades, the city has experienced lots of change due to socioeconomic development, for example, during 1975-2012 urban lands and population has grown fourfold and sixfold, respectively. Consequently, this rapid development has increased the demand for residential and infrastructure development [56]. Bandar Abbas coastline is subjected to SLR, regular tide, wave set-up, and wind set-up. Hormozgan province, where Gonu tropical cyclone took place in the Arabian Sea, also is impacted by storm surges. In the latest incident (2007), the cyclone caused around \$215 million asset damage and 23 fatalities along the Persian Gulf and Oman Sea [57]. There are also many protection structures, mainly seawalls and breakwaters, in the city coastline to prevent coastal flooding.

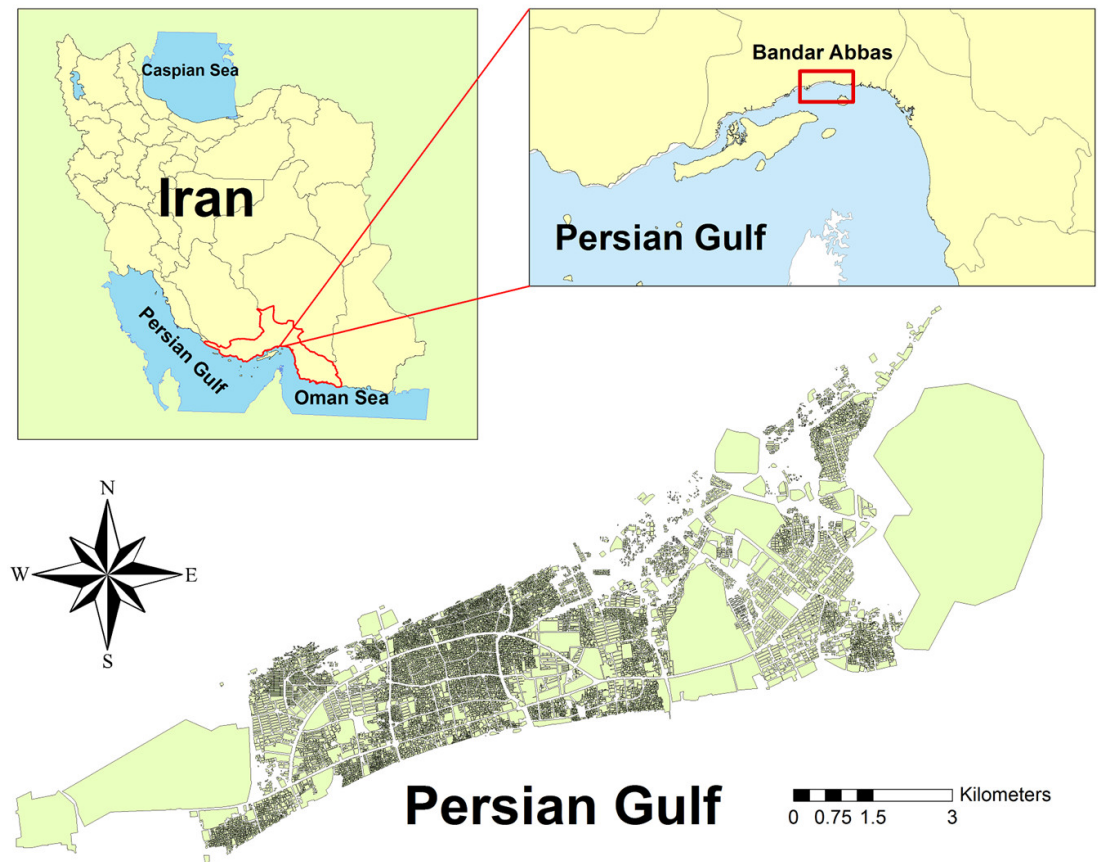

Figure 1. Location of the study area, Bandar Abbas City, Iran. 


\section{Materials and Methods}

Following the Equation (1), to develop the coastal flooding risk index, this study focuses on (i) hazard: a combination of SLR and factors triggering coastal flooding (storm surge, wave set-up, wind set-up, and tidal range), (ii) social vulnerability: the degree to which people are susceptible to or unable to cope with, respond to, or recover from hazard events [8], and (iii) exposure: population density.

$$
\text { Flood risk }=\text { Hazard } \times \text { Vulnerability } \times \text { Exposure }
$$

In this study, the coastal flooding risk assessment of Bandar Abbas City was conceptualized through a SMCDA framework. It supports risk analysis by integrating a large number of temporal and spatial data, in a linear trend [42]. To apply the multi-criteria decision analysis (MCDA) approach, first risk indicators were selected, and then proxy variables (i.e., alternative measurable variables for selected indicators) were identified. Subsequently, both indicators and proxy variables were structured into a hierarchical form (i.e., hazard, vulnerability, and exposure). Secondly, the AHP model and min-max approach were employed to weight risk indicators and normalize proxy variables, respectively. Finally, different types of spatial analyses were applied to integrate weighted indicators and normalized proxy variables to map risk under flooding scenarios. This proposed approach can provide valuable information that supports decision-makers and local organizations to design effective and customized strategies to mitigate flood risk and damages. Figure 2 shows a schematic view of the adopted methodology.

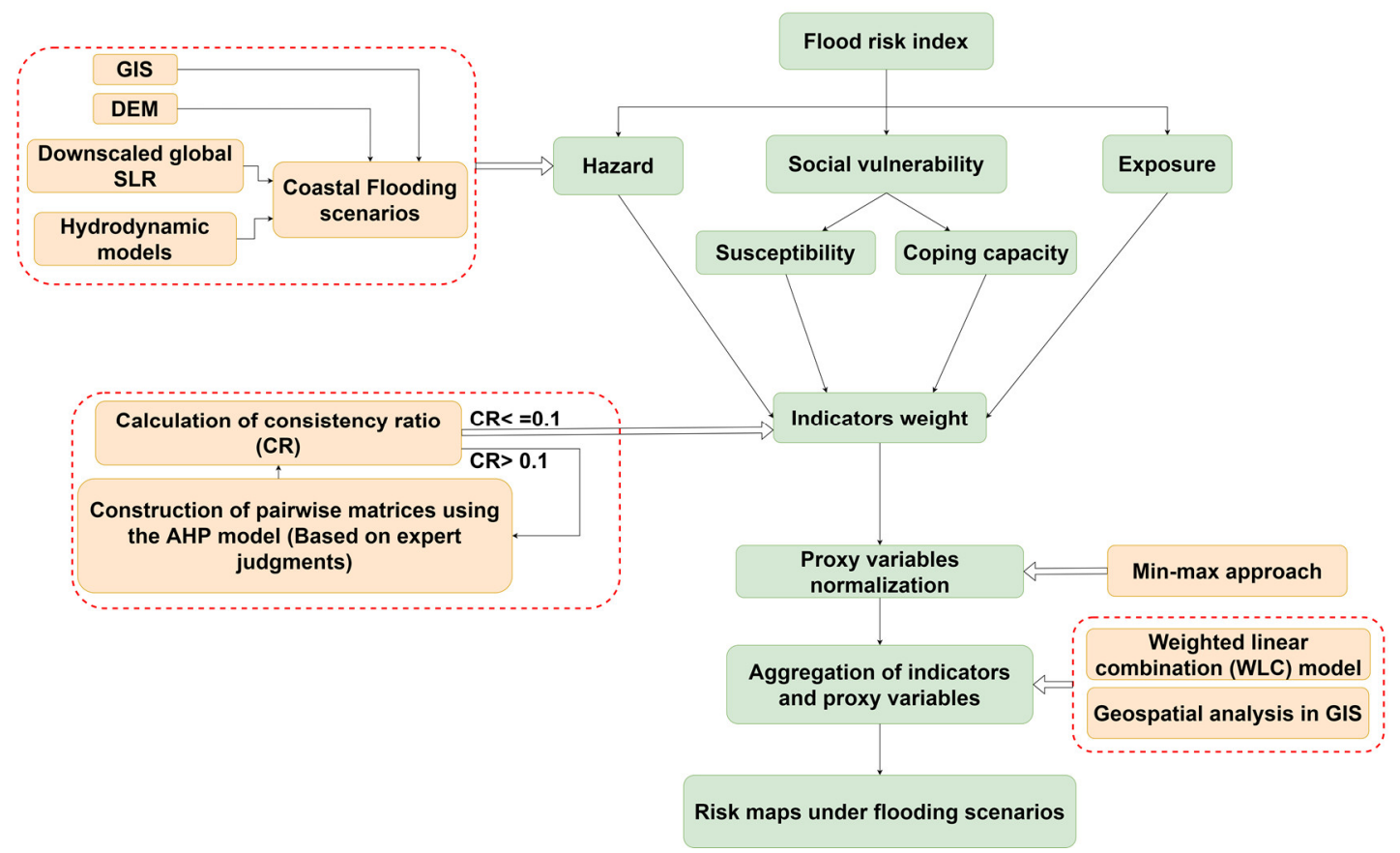

Figure 2. The adopted methodology of the study.

\subsection{Indicators and Proxy Variables Selection and Derivation}

\subsubsection{Hazard Component}

According to experts' opinion, hazard indicators including SLR as a consequence of climate change, and other triggering factors of coastal flooding, that is, tidal range, wave set-up, wind set-up, and storm surge, were identified to map flood hazard. The IPCC represents four scenarios, on the basis of representative concentration pathways (RCPs), including RCP 2.6, RCP 4.5, RCP 6, and RCP 8.5 to estimate permanent SLR at a global scale by 2100 [58]. In this study, to achieve a more realistic value of SLR, global RCPs scenarios were downscaled based on a previous study [59]. Finally, the average of 
RCP 2.6 and RCP 8.5 was applied in 2050 and 2100. For the other triggering factors related to coastal flooding, hydrodynamic models (MIKE 21) were employed to derive hazard indicators. In this regard, the tidal range indicator represents the mean higher high water (MHHW), while wave set-up, wind set-up, and storm surge indicators were identified based on 50 and 100 year return periods $[35,60]$.

The ALOS PALSAR digital elevation model (DEM) with $12.5 \mathrm{~m}$ spatial resolution, provided by the Alaska Satellite Facility Distributed Active Archive Data Center (ASF DAAC), was used to map coastal flooding areas [61]. Establishing flooding scenarios addresses high uncertainties associated with flood risk projections in the future [62]. As such, in this study, various flooding scenarios were defined in 2050 and 2100, that is, S0: the baseline scenario at present just considering temporarily SLR to S2-2100: the worst-case scenario by summing SLR caused by climate change with MHHW, wave set-up, wind set-up, and storm surge (Table 1). For calculating the coastal inundation areas, a GIS-based flood modeling was used to combine the DEM of the study area with different flooding scenarios. In each scenario, those areas that had lower elevation than extreme sea levels, and were hydraulically connected to the sea or open water, were considered as inundated areas [63]. Various flood characteristics (e.g., depth, duration, velocity, and timing of flood) affect the flood damage. However, inundation depth is recognized as the most important factor in physical damages [64]. Therefore, in this study, flood depth was identified as the proxy for flood hazard indicators.

Table 1. Flooding scenarios in the study area.

\begin{tabular}{|c|c|c|c|c|c|}
\hline Scenarios & Permanent SLR (cm) & & \multicolumn{2}{|c|}{ Temporary Sea Level (cm) } & Total $(\mathrm{cm})$ \\
\hline So & 0 & & $\begin{array}{l}\text { Wave and wind set-up } \\
\text { (50 year return periods) }+ \\
\text { MHHW }\end{array}$ & 259 & 259 \\
\hline S1 (2050) & Average (RCP2.6 and RCP8.5) & 25 & \multirow{2}{*}{$\begin{array}{l}\text { Wave and wind set-up } \\
\text { (100 year return periods) } \\
+\mathrm{MHHW}\end{array}$} & \multirow{2}{*}{320} & 345 \\
\hline S1 (2100) & Average (RCP2.6 and RCP8.5) & 61 & & & 381 \\
\hline S2 (2050) & Average (RCP2.6 and RCP8.5) & 25 & \multirow{2}{*}{$\begin{array}{l}\text { Wave and wind set-up } \\
\text { (100 year return periods) } \\
+ \text { MHHW + storm surge }\end{array}$} & \multirow{2}{*}{470} & 495 \\
\hline S2 (2100) & Average (RCP2.6 and RCP8.5) & 61 & & & 531 \\
\hline
\end{tabular}

\subsubsection{Vulnerability Component}

After reviewing existing literature and given data availability, four sociodemographic indicators were selected for both susceptibility and coping capacity sub-components [25,65-67]. Accordingly, population, age, and gender represent the susceptibility of people due to hazard events. The relevant proxy variables were also applied for each susceptibility indicator: (i) population: population density (the total number of people living in a specific area) and population with disability, (ii) age: people over 65 years and under five years, and (iii) gender: females. For coping capacity, socioeconomic status was defined as an indicator. Two proxy variables were then considered, that is, people with high school diplomas and employment, for this indicator. For both susceptibility and coping capacity sub-components, secondary data at the census block level were collected from the Iranian Statistics Center [55].

\subsubsection{Exposure Component}

Population density is the most significant indicator of flood exposure since it directly describes human settlements [68]. In this study, like the vulnerability component, the population density was chosen as a proxy variable for population indicator. The population density was selected for exposure and vulnerability components as it contributes to two different ways to assess flood risk. In the context of flood exposure, the number of affected people is important and it is determined based on the intersection of population density with inundation data. In other words, the higher population density will result in higher exposure to people. In the context of social vulnerability, the role of people density 
is a bit different than in the exposure component. In this sense, population density is important as high population density may have a burden on evacuation time and will be more affected by a flood. Table 2 shows all identified indicators and associated proxy variables. The positive and negative impacts of proxy variables on flood risk are also expressed by "+" and " - " signs, respectively.

Table 2. Risk components, sub-components indicators, proxy variables and their impacts on the flooding risk index.

\begin{tabular}{|c|c|c|c|c|c|}
\hline Risk Components & Sub-Components & Indicators & Proxy Variables & Impacts & Reference \\
\hline Hazard & & $\begin{array}{c}\text { SLR } \\
\text { Tidal range } \\
\text { Wave set-up } \\
\text { Wind set-up } \\
\text { Storm surge }\end{array}$ & Inundation depth (m) & + & {$[21,69]$} \\
\hline \multirow{7}{*}{ Social vulnerability } & \multirow{5}{*}{ Susceptibility } & \multirow[b]{2}{*}{ Population } & Population density (\%) & + & {$[49,68,70]$} \\
\hline & & & $\begin{array}{l}\text { Population with any sort } \\
\text { of disability (\%) }\end{array}$ & + & {$[25,71]$} \\
\hline & & & $\begin{array}{c}\text { Children }<5 \text { years old } \\
(\%)\end{array}$ & + & \multirow[b]{2}{*}[67,72]{} \\
\hline & & Age & $\begin{array}{l}\text { Elderly people > } \\
65 \text { years old }(\%)\end{array}$ & + & \\
\hline & & Gender & Female (\%) & + & {$[25,53]$} \\
\hline & \multirow[b]{2}{*}{$\begin{array}{l}\text { Coping } \\
\text { capacity }\end{array}$} & \multirow[b]{2}{*}{$\begin{array}{l}\text { Socioeconomic } \\
\text { status }\end{array}$} & Employment (\%) & - & {$[25,66]$} \\
\hline & & & $\begin{array}{l}\text { People with high school } \\
\text { diploma (\%) }\end{array}$ & - & [25] \\
\hline Exposure & & Population & Population density (\%) & + & {$[31,49,72]$} \\
\hline
\end{tabular}

\subsection{Spatial MCDA Approach}

\subsubsection{Normalizing Proxy Variables}

All input data are different in magnitude and dimension. Therefore, to integrate them into SMCDA, they should be normalized to range from zero to one [73]. This study applied two equations to normalize vulnerability and exposure components depending upon the positive or negative impacts of proxy variables on flood risk. Accordingly, a min-max rescaling approach (Equations (2) and (3)) was applied to normalize the value of positive and negative proxy variables, respectively $[74,75]$.

$$
\begin{aligned}
& \left(V_{i}\right)_{j}=\frac{X_{i}-X_{\min }}{X_{\max }-X_{\min }} \\
& \left(V_{i}\right)_{j}=\frac{X_{\max }-X_{i}}{X_{\max }-X_{\min }}
\end{aligned}
$$

\subsubsection{Weighting Indicators}

In the field of flood risk assessment, the AHP model as a type of MCDA approach has been frequently applied [76]. The AHP model was initially introduced by Saaty [41], and as a flexible method that can solve complicated decision-making problems involving qualitative data [77].

In the AHP model, as the first step, the MCDA problem is structured into a hierarchical form at least in three levels: (i) objective at the top, (ii) criteria which describe the objectives in the middle, and (iii) alternatives at the bottom level. In the second step, at each level, a pairwise comparison is applied for constructing a decision matrix. It transforms qualitative data into a fixed value and makes the process able to be handled effectively and simply [78]. To make a pairwise comparison matrix (PCM), Saaty [41] represented a standardized measurement scale ranging from 1 to 9 , where one means there 
is no difference in the criterion importance, and nine shows one criterion is much more important than others (See Table 3).

Table 3. The importance of indicators in pairwise comparisons based on the analytical hierarchy process (AHP) model [41].

\begin{tabular}{cc}
\hline Intensity of Importance & Degree of Preference \\
\hline 1 & Equally important \\
3 & Moderately more important \\
5 & Strongly more important \\
7 & Very Strongly more important \\
9 & Extremely more importance \\
$2,4,6,8$ & Intermediate values \\
\hline
\end{tabular}

Furthermore, to show an inverse relationship, reciprocal numbers can be used. Pairwise comparison of $\mathrm{n}$ criteria is shown in a matrix as follows [41]:

$$
A=\left[\begin{array}{cccc}
a_{11} & a_{12} & \ldots & a_{1 n} \\
a_{21} & a_{22} & \ldots & a_{2 n} \\
a_{31} & a_{32} & \ldots & a_{3 n} \\
\ldots & \ldots & \ldots & \ldots \\
\ldots & \ldots & \ldots & \ldots \\
a_{m 1} & a_{m 2} & \ldots & a_{m n}
\end{array}\right], a_{i i}=1, a_{j i}=\frac{1}{a_{i j}}, a_{i j} \neq 0
$$

Finally, an eigenvector technique is employed to solve the reciprocal matrix and calculate the relative importance of criteria. The AHP quality outputs can be measured by consistency of PCM, and thus the consistency index (CI) is identified according to Equation (5) [41]:

$$
\mathrm{CI}=\frac{\lambda_{\max }-\mathrm{n}}{\mathrm{n}-1}
$$

where $\lambda$ max and $n$ are the maximum eigenvalue and order of matrix $A$, respectively. Further, the final consistency ratio (CR) is calculated based on Equation (6) as follows [41]:

$$
\mathrm{CR}=\frac{\mathrm{CI}}{\mathrm{RI}}
$$

where $\mathrm{RI}$ is a random index, that is, the consistency index of a randomly generated pairwise comparison matrix, which is dependent on the number of criteria $(\mathrm{N})$ that are being compared and is determined based on Table 4.

Table 4. Random index (RI) values used to compute the consistency ratio (CR) [41].

\begin{tabular}{cccccccccccc}
\hline $\mathbf{N}$ & $\mathbf{1}$ & $\mathbf{2}$ & $\mathbf{3}$ & $\mathbf{4}$ & $\mathbf{5}$ & $\mathbf{6}$ & $\mathbf{7}$ & $\mathbf{8}$ & $\mathbf{9}$ & $\mathbf{1 0}$ & $\mathbf{1 1}$ \\
\hline $\mathrm{RI}$ & 0 & 0 & 0.58 & 0.9 & 1.12 & 1.24 & 1.32 & 1.41 & 1.45 & 1.49 & 1.51 \\
\hline
\end{tabular}

It is recommended that the CR values are less than 0.1 ; otherwise, pairwise comparisons are inconsistent, and judgments need to be revised to yield meaningful results [41].

In this study, to calculate the weight of indicators, questionnaires were given to twelve experts who specialized in coastal engineering, social, and climate change science. In order to incorporate a wide range of opinions, this study selected experts from academia (four people), government agencies (three people), and research institutions at the national and local levels (five people). Finally, they were asked to express their judgments and filled the questionnaire. A geometric mean was then applied to integrate individuals' judgments. 


\subsubsection{Aggregation Method}

In the SMCDA, the weighted linear combination (WLC) as a straightforward overlay approach has been commonly used [35,79-81]. It is easily understandable by decision-makers and can be linked to spatial data [42]. In this study, a WLC model was separately applied to each risk component (hazard, vulnerability, and exposure) for constructing indexes based on Equation (7) [42]:

$$
\mathrm{Rc}=\sum_{\mathrm{i}=1}^{\mathrm{n}} \mathrm{X}_{\mathrm{i}} \times \mathrm{W}_{\mathrm{i}}
$$

where Rc is the value of each risk component, $W_{i}$ is the weight of each indicator derived by the $\operatorname{AHP}\left(\mathrm{W}_{\mathrm{i}}<1\right.$ and $\left.\sum_{\mathrm{i}=1}^{\mathrm{n}} \mathrm{W}_{\mathrm{i}}=1\right)$, and $\mathrm{X}_{\mathrm{i}}$ is the normalized proxy variables. Finally, the value of each component risk calculated above is used as an input for the risk formulation (Equation (1)) to build a coastal flooding risk index.

This study used Expert Choice software (version 11.5) to calculate indicators' weight by the AHP model. ArcGIS 10.6 also was utilized to develop a spatial database and the required raster layers. Given the spatial resolution of input data, a $30 \mathrm{~m}$ cell size of raster layers was used for generating flood risk maps under various flooding scenarios.

\section{Results}

\subsection{Flood Hazard Analysis}

The first component of risk, flood hazard, was analyzed considering five selected indicators including SLR, tide, wave set-up, wind set-up, and storm surge along with flood depth as a proxy variable. This study employed geospatial techniques to create flood inundation maps considering flood hazard indicators' weight calculated by the AHP model (Table 5). The consistency ratio of flood hazard PCM was also identified in an acceptable range (0.02).

Table 5. Pairwise comparison matrix of flood hazard indicators in Bandar Abbas City.

\begin{tabular}{ccccccc}
\hline Hazard & $\begin{array}{c}\text { Wave } \\
\text { Set-Up }\end{array}$ & $\begin{array}{c}\text { Wind } \\
\text { Set-Up }\end{array}$ & SLR & $\begin{array}{c}\text { Storm } \\
\text { Surge }\end{array}$ & Tide & $\begin{array}{c}\text { Weight by the } \\
\text { AHP Model }\end{array}$ \\
\hline Wave set-up & 1 & $1 / 2$ & $1 / 3$ & $1 / 2$ & $1 / 3$ & 0.087 \\
Wind set-up & 2 & 1 & $1 / 2$ & $1 / 2$ & $1 / 2$ & 0.137 \\
SLR & 3 & 2 & 1 & 1 & $1 / 2$ & 0.224 \\
Storm surge & 2 & 2 & 1 & 1 & $1 / 2$ & 0.209 \\
Tide & 3 & 2 & 2 & 2 & 1 & 0.343 \\
\hline
\end{tabular}

The flood extent and depth in Bandar Abbas City under flooding scenarios are shown in Figure 3 with five classifications ranging from very low to very high. In all scenarios, the flooded areas were mostly identified adjacent to the coast, including the western, eastern, and central parts of the study area. The total flooded areas under scenarios S0, S1-2050, S2-2050, S1-2100, and S2-2100 were estimated $5.4 \%, 5.4 \%, 8.2 \%, 15.6 \%$, and $21.2 \%$, respectively. 

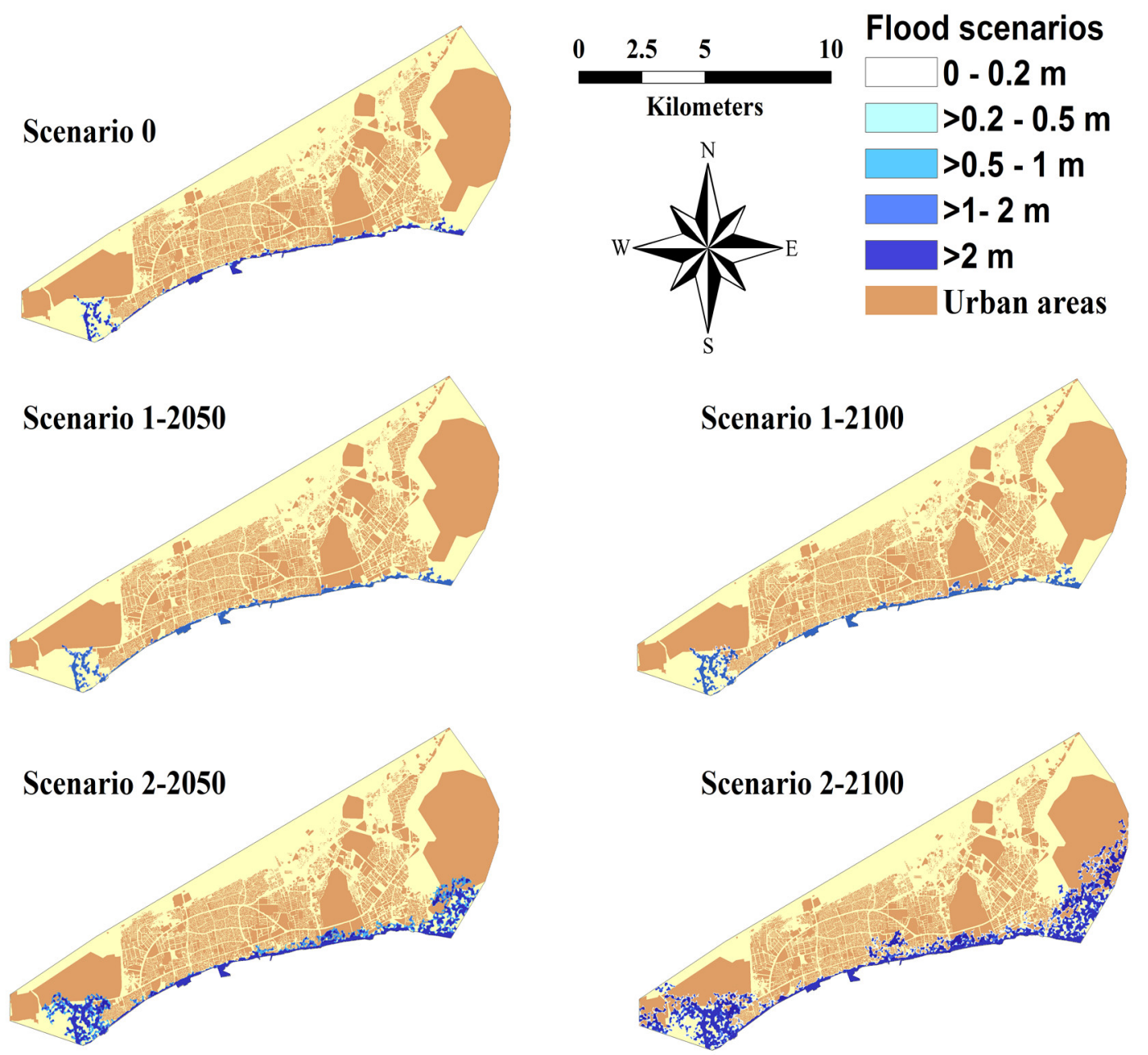

Figure 3. Flooded areas under various scenarios in Bandar Abbas City.

\subsection{Vulnerability Analysis}

The same approach as with the flood hazard component was applied to the social vulnerability component to calculate the relative importance of susceptible indicators, as shown in Table 6. The CR of susceptibility matrix was calculated as 0.02 , as such, indicator weights can be considered suitable to create the social vulnerability index. However, for coping capacity, a PCM was not considered to determine indicators' weight as socioeconomic status was only contributed as an indicator.

Table 6. The relative importance of susceptibility indicators in Bandar Abbas City.

\begin{tabular}{ccccc}
\hline Susceptibility & Population & Gender & Age & Weight by the AHP Model \\
\hline Population & 1 & 3 & 1 & 0.44 \\
Gender & $1 / 3$ & 1 & $1 / 2$ & 0.17 \\
Age & 1 & 2 & 1 & 0.39 \\
\hline
\end{tabular}

The susceptibility and coping capacity proxy variables, shown in Table 2, were normalized to map the social vulnerability. Accordingly, the WLC model was used to integrate weighted social indicators and normalized proxy variables where the weight of susceptibility and coping capacity sub-components, calculated by the AHP model, were estimated as 0.75 and 0.25 , respectively. The result of social vulnerability mapping is displayed in Figure 4, where very low, low, medium, high, and very high vulnerability classes cover about $29.5 \%, 15.9 \%, 9.2 \%, 1.7 \%$, and $43.7 \%$ of the study area, respectively. 


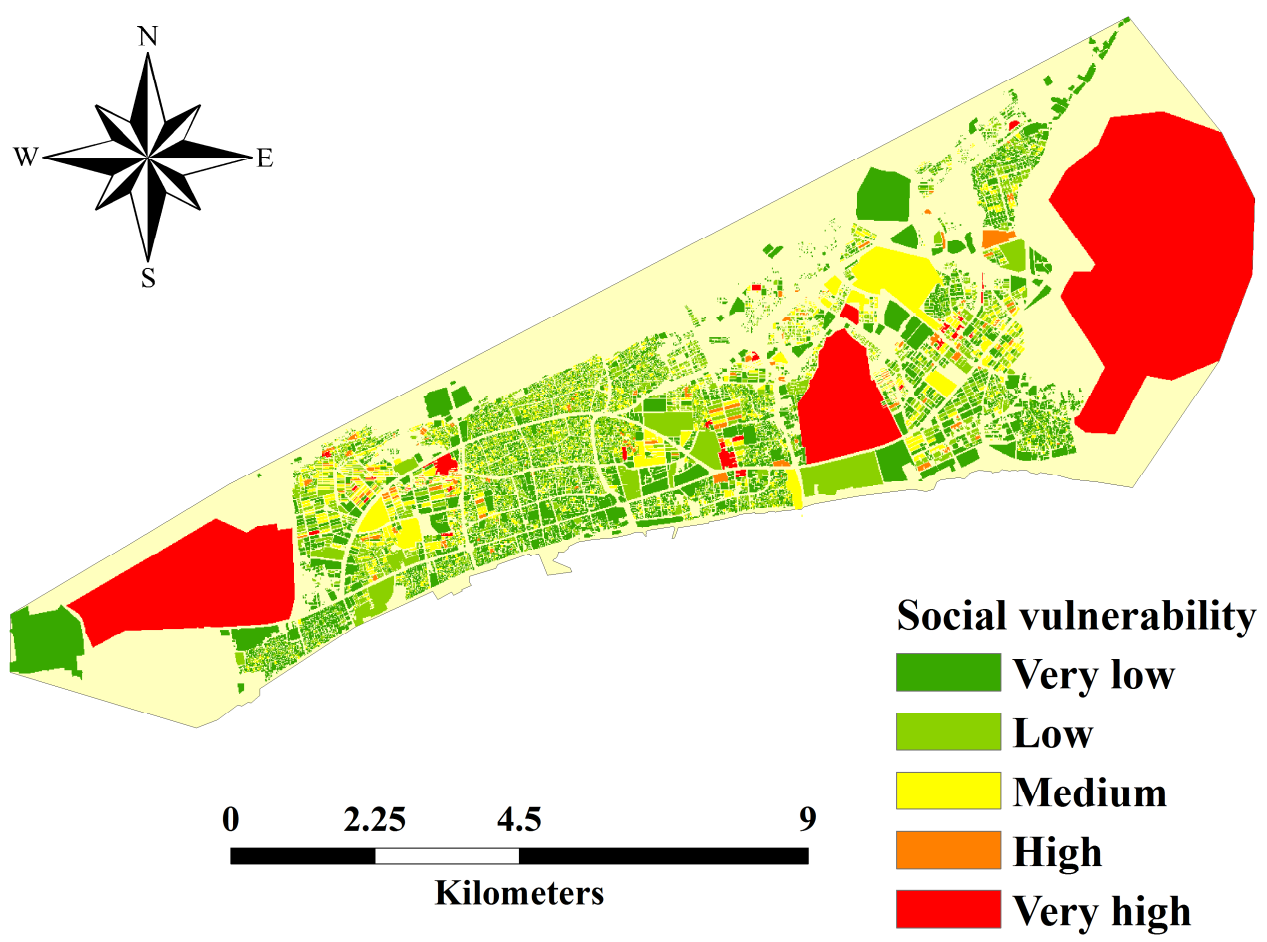

Figure 4. The spatial pattern of social vulnerability in Bandar Abbas City.

\subsection{Exposure Analysis}

In this study, the flood exposure map was determined on the basis of normalized population density. It was then classified into five categories, which are shown in Figure 5. Given the flood exposure map, $45.2 \%$ of the study area was found in very low exposure, followed by low $(42 \%)$, medium $(12 \%)$, high $(0.65 \%)$, and very high $(0.15 \%)$. As can be observed from Figure 5, exposed people living close to the coastline are mainly distributed in low-to-medium exposure, including regions located in the west and middle of Bandar Abbas City.

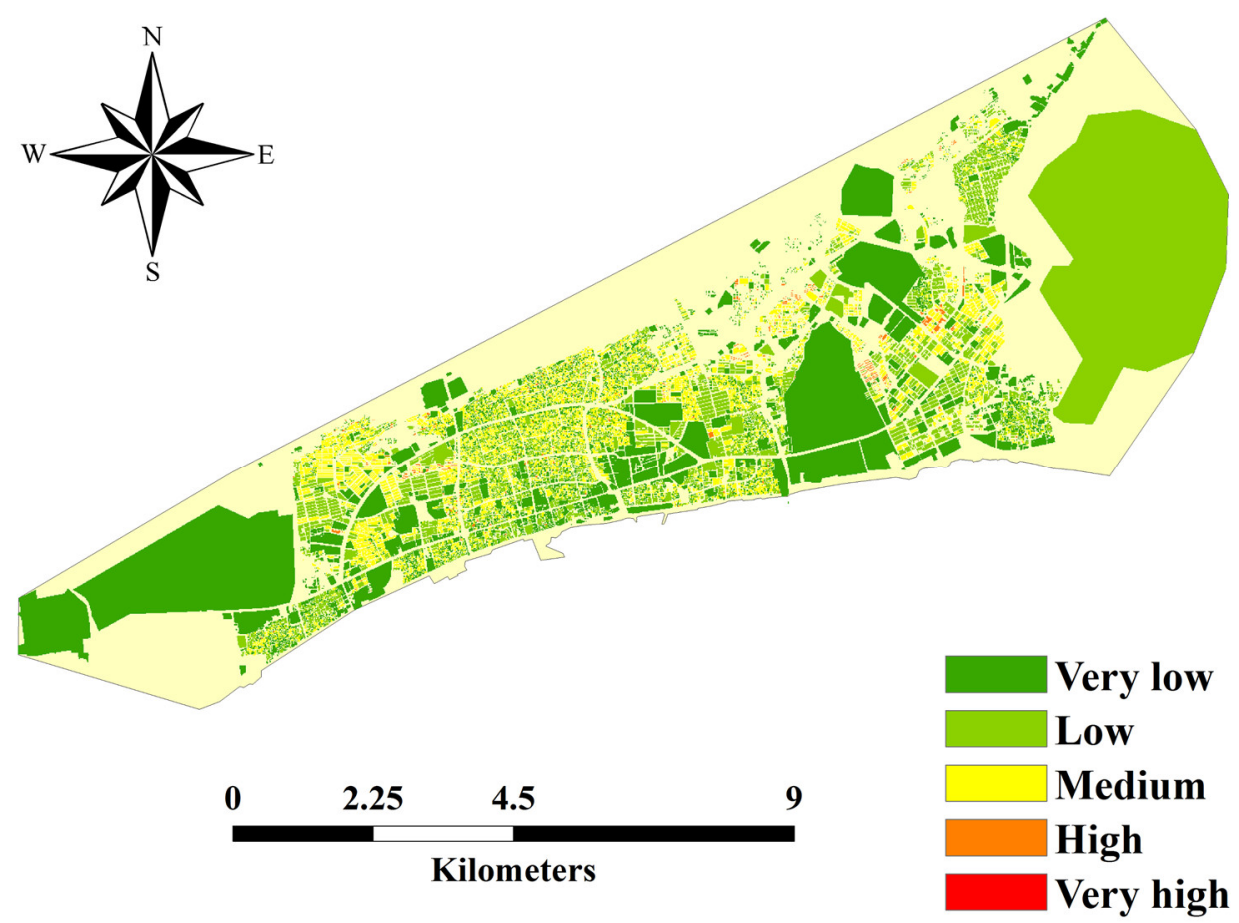

Figure 5. Distribution of population exposure in Bandar Abbas City. 


\subsection{Flood Risk Assessment}

A social vulnerability map only shows where vulnerable people are located without considering the extent of flood hazard and exposure. To address the risk potential of people under flooding scenarios, flood hazards, social vulnerability, and exposure maps were combined using GIS (Figure 6). Flood risk maps were then classified into five vulnerability levels using the Jenks natural break technique. The overall percentage areas in each category were summarized, as shown in Table 7.
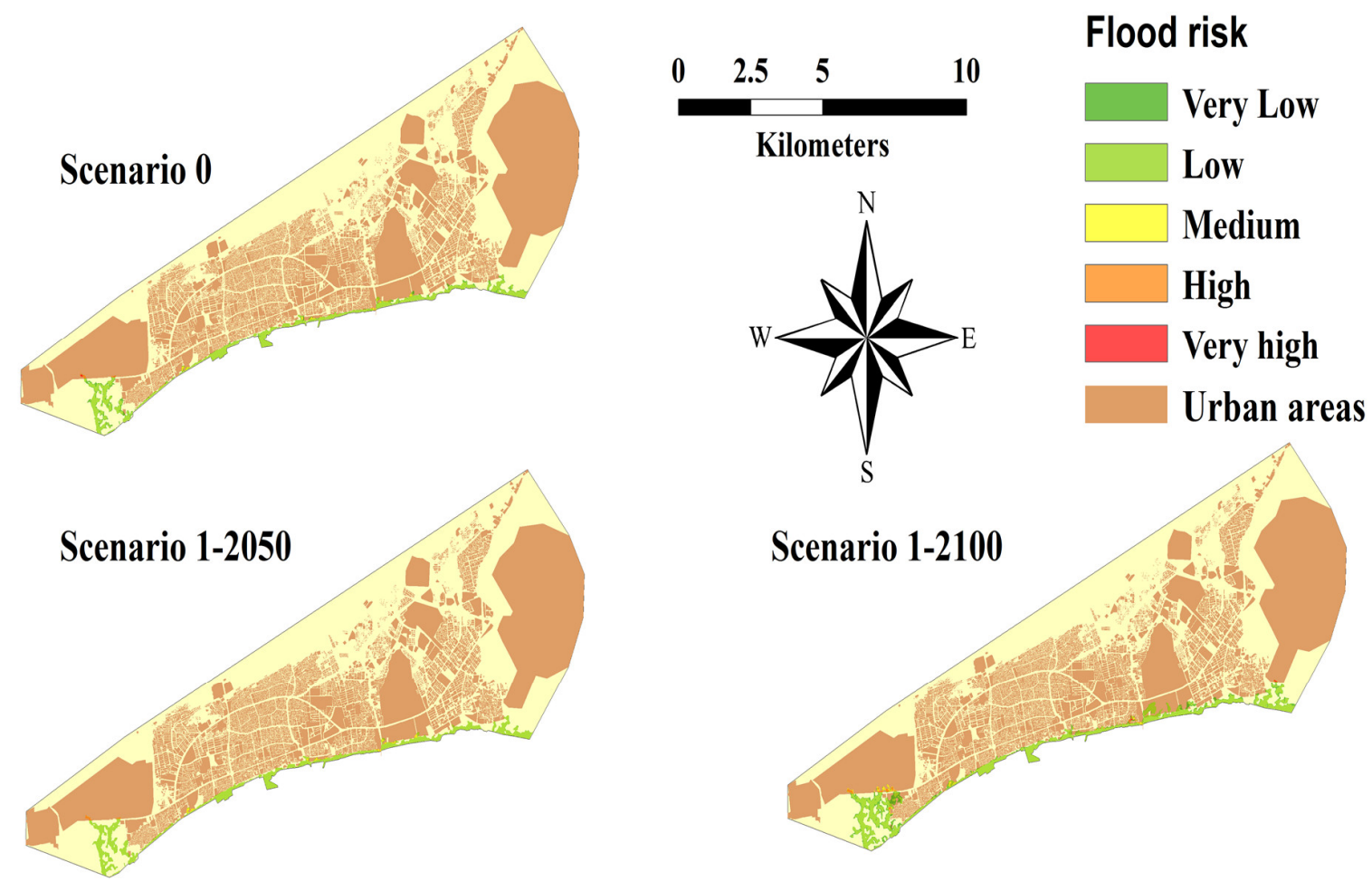

Flood risk
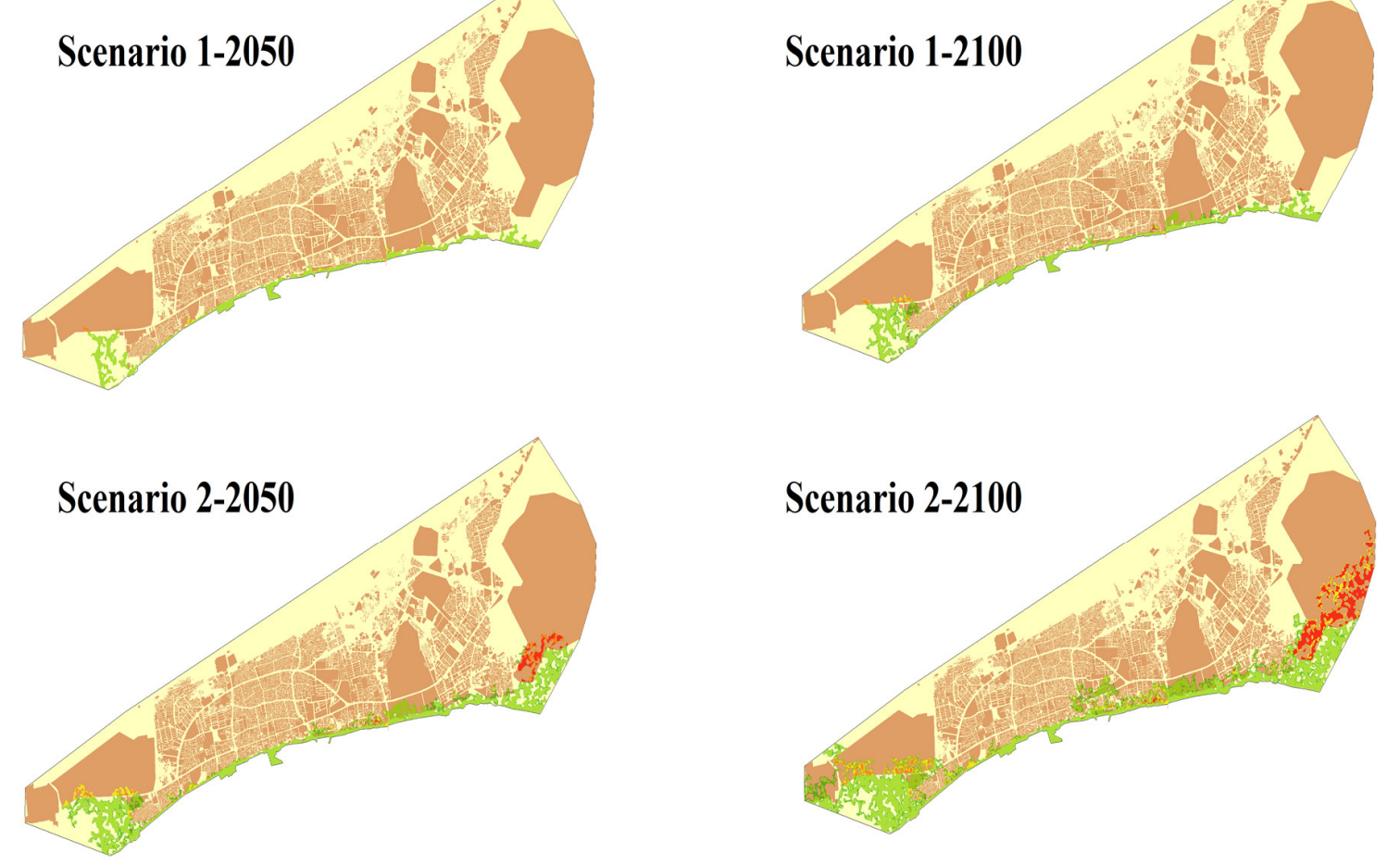

Figure 6. Coastal flooding risk under various scenarios in Bandar Abbas City.

Table 7. Percentage area of risk classes for various coastal flooding scenarios.

\begin{tabular}{cccccc}
\hline \multirow{2}{*}{$\begin{array}{c}\text { Flooding } \\
\text { Scenarios }\end{array}$} & \multicolumn{5}{c}{ Risk Value (\%) } \\
\cline { 2 - 6 } & Very Low & Low & Medium & High & Very High \\
\hline S0 & 16.9 & 79.9 & 1.8 & 0.8 & 0.4 \\
S1-2050 & 2.1 & 93.7 & 3 & 1 & 0.2 \\
S1-2100 & 20 & 75 & 2.7 & 1.8 & 0.5 \\
S2-2050 & 20.1 & 64.5 & 4.8 & 5.5 & 5.1 \\
S2-2100 & 18.3 & 57.3 & 9.6 & 2.5 & 12.3 \\
\hline
\end{tabular}


As the results show, for scenario S0 to S1-2100, more than 95\% of flooded areas were found in very low to low risks, while in scenario S2-2050 to S2-2100 the areas identified as the medium, high, and very high value of risk increased. For example, in scenario S2-100, approximately $24.4 \%$ of flooded urban areas were classified in medium to very high risk zones, mostly located in the eastern and western parts of Bandar Abbas City, which is consistent with the flooded areas.

In this study, model validation, based on field observation data, was not carried out due to a lack of data on extreme flood events in Bandar Abbas City. Instead, sensitivity analysis as a common technique in the MCDA was employed to validate the flood hazard and risk index reliability [47,82-85]. The sensitivity analysis determines how changing input indicators' weight will affect the model outputs [86]. In this regard, for each flood scenario, an indicator weight was changed $( \pm 10 \%)$. The weight of other indicators was adjusted because the sum of indicators' weight should remain equal to one [86]. The sensitivity analysis was then applied to all indicators, and a little change was seen in model outputs in comparison with the initial conditions for all scenarios. It confirms that the flood risk index outputs are reliable.

\section{Discussion}

In this study, a GIS-based SMCDA was used to assess coastal flooding risk due to a combination of SLR and triggering flooding factors under flooding scenarios. Weighted hazard, exposure, and vulnerability indicators, by applying the AHP model, and associated proxy variables were integrated in a linear way using spatial analysis techniques. It should be noticed that the usage of the AHP as an efficient model has been confirmed with several studies in the field of flood hazard and risk assessments $[49,53,87]$. Many flood-triggering factors, that is, those related to hydrodynamic conditions, in combination with climate change-induced SLR play a significant role to construct a coastal flood hazard index [54]. In this study, five indicators: climate change-induced SLR, wave set-up, wind set-up, tidal range, and storm surges were selected.

The importance of each triggering indicator should be determined by decision-makers as they contribute differently to prepare a flood hazard map. In this context, our study focused on experts' judgment to consider indicators that have significant effects on flood extent, and depth distribution. The AHP model was used to determine the importance of the flood-related indicators based on the experts' judgment. Results showed that the most significant indicator that contributes to the flood occurrence is tidal range, followed by SLR, storm surges, wind set-up, and wave set-up. This could be attributed to the fact that high tidal range, twice in a day, and permanent SLR happen more frequently compared with other triggering indicators. In all scenarios, our modeling shows that flooding extent covers the areas mostly located near the coast, and within the eastern, western, and some central parts of Bandar Abbas City. Furthermore, inundated areas were widely found in high and very high hazard classes which mainly correspond to (i) the gentle slope and low-elevations areas extracted by the DEM analysis in these areas, and (ii) lack of protection structures such as seawalls and breakwaters, especially in the west and east of the City.

As Figure 4 shows, the social vulnerability has not been uniformly distributed within the study area, and all vulnerability classes were found in some small neighborhoods. It indicates that assessing social vulnerability at the census block level will provide more insights into socioeconomic characteristics, which could be lost at a large scale. In the pre-disaster phase, the socioeconomic status of people can significantly influence their ability to cope with or respond to a disaster [88,89]. It helps decision-makers in providing suitable mitigations and adaption measures depending upon the vulnerable people in an affected area. In terms of social vulnerability, the medium, high, and very high vulnerable classes covered $54.6 \%$ of the study area, mostly located in the eastern, western, and slightly in the middle of the study area. It can be attributed to the high values in both susceptibility indicators' weights and normalized proxy variables. On the one hand, in these areas, the susceptibility of proxy variables such as people with disabilities, people under five years old, and females were identified in high and very high susceptible classes. On the other hand, the AHP implication revealed that the most significant 
indicators that contribute to building social vulnerability index are population and age, which is in line with previous studies $[70,72,90,91]$.

It is worth pointing out that in flooded areas, socioeconomic proxy variables, that is, employment and people with high school diplomas, were also categorized in high and very high classes. It can increase the people's coping capacity and minimize social vulnerability. However, the coping capacity received considerably less weight (0.25) as compared with the susceptibility (0.75). Accordingly, it was unable to moderate the social vulnerability values to very low, low, or medium classes. In contrast, the coping capacity of the most nonflooded districts was identified as the lowest value. It is related to the spatial distribution of employment and people with high school diplomas, where they were mostly characterized in very low and low levels. These findings confirm that proper attention should be taken into account to improve the coping capacity level in these less adaptable coastal districts. The coping capacity can be enhanced by providing employment opportunities, alternative sources of income, and improving the level of education. The study presented here provides spatially detailed social vulnerability in flood-prone areas, which can assist decision-makers to apply the most appropriate mitigation measures to reduce vulnerability for a specific social group in a neighborhood or household level [31].

Given the results shown in Table 7, small areas were found in high and very high flood risk levels (eastern, western, and middle parts of coastal zones) compared with the other risk classes. It is mainly due to the existence of the number of very high flood hazard zones, medium population density, and medium to very high social vulnerability. A constant trend was also seen from scenario S0 to scenario S2-100, where the percentage of very low-to-low classes of risk decreased. In contrast, the medium to very high classes of risk dramatically increased, particularly in S2-2050 and S2-2100. This sudden increase could be due to the following reasons: (i) more flooded areas were identified, which mainly were classified into high and very high values, (ii) the social vulnerability in flooded areas was recognized as medium to high due to high susceptibility and low coping capacity, and (iii) the population exposure in flooded areas was identified in medium values. Accordingly, essential preparation and mitigation measures should be implemented in high-risk zones by decision-makers to minimize flood risk consequences.

There was no flooding risk map in the study area; therefore, the developed methodology herein could not be validated based on field observation. A sensitivity analysis was alternatively conducted to investigate the flood risk index accuracy that shows how sensitive the flooding risk maps are to changes in indicators' weight. Sensitivity analysis results show that changing the weight of certain indicators (i.e., hazard, social vulnerability, and exposure) will result in different risk classes in final risk maps. For example, indicators such as SLR, tidal range, population, age, and socioeconomic indicators were more sensitive to changing initial weights. It proves the importance of these indicators as key flood risk indicators. In contrast, wave set-up, wind set-up, and gender were less sensitive compared with the other indicators discussed above. This finding shows that the sensitivity analysis would be beneficial to determine the influence of each indicator to develop flood risk maps.

\section{Conclusions}

The objective of this study was to develop a flooding risk index due to SLR and coastal flooding in Bandar Abbas City, Iran. In this regard, a GIS-based SMCDA method as a semiquantitative method was employed. Nine indicators were selected and then classified into three main flood risk components including hazards: SLR, storm surge, wave set-up, wind set-up, and tidal range; social vulnerability: gender, population, and age; and exposure: population. The flood risk analysis was based on the integration of multiple indicators and proxy variables, where the weight of indicators was derived using the AHP model.

Flooding scenarios presented herein combine the climate change-induced SLR with the other coastal flooding triggers to map flood risk. These maps can be considered as an effective tool for risk reduction. It supports decision-makers to take suitable actions under different risk conditions, 
particularly in the pessimistic scenario, where the highest level of flood hazard happens. The fine resolution demographic data employed here (at the census block level) resulted in a thorough assessment of social vulnerability in flooded areas. Obtained social vulnerability results exhibited a high contribution of susceptible indicators such as population and age compared with the gender. In contrast, the coping capacity received relatively less weight than the susceptibility. Consequently, $45.4 \%$ of Bandar Abbas City districts were classified as high and very high vulnerable areas, mostly located in the eastern, western, and central parts. Considering the future flooding scenarios, a notable increase was seen in high and very high risk classes. Therefore, to reduce future social vulnerability, the coping capacity of people should be enhanced by creating more employment opportunities or increasing levels of education. The spatial distribution of social vulnerability can help decision-makers to choose suitable measures to reduce the adverse effect of hazard floods. For example, where the high social vulnerability is mainly caused by the existence of elderly, children, or disabled people, providing flood protection structures is more effective than using individual mitigation measures. Accordingly, linking social vulnerability as a key element to flood risk analysis is required to improve risk management strategies.

The semiquantitative method used in this study is a process that can be also employed to develop the flood risk index of physical assets. It would be much more beneficial particularly in developing countries, where using statistical methods and running physical models to simulate coastal flooding and building physical vulnerability curves is challenging, due to the reliability and availability of data. In other words, the integration of weighted indicators and associated proxy variables, based on experts' opinion, can be applied instead of quantitative models that are costly, time-consuming, and complicated to run. The SMCDA is flexible in handling a large number of qualitative or quantitative indicators to map flood risk and can be regularly updated by adding or modifying indicators since many indicators are changing over time. In the absence of flood hazard filed data, the model accuracy can be tested by the sensitivity analysis, where the application of this technique in our study proved the model's reliability. Flood risk map generated by the SMCDA provides a comprehensive database that can allow decision-makers and stakeholders to propose mitigation plans for flood risk reduction.

Of course, this study has limitations that can be addressed in future research. To generate more accurate and customized results, further studies could incorporate relevant indicators of exposure and social vulnerability components such as land use, infrastructures and lifelines, and income. This study only focused on social vulnerability, while linking physical or economic dimensions to social vulnerability leads to more efficient flood risk reduction strategies.

Author Contributions: Investigation, V.H.; Methodology, V.H.; Software, V.H.; Supervision, F.V. and K.D.; Validation, V.H.; Writing-original draft, V.H.; Writing-review and editing, F.V. and K.D. All authors have read and agreed to the published version of the manuscript.

Funding: This research received no external funding.

Conflicts of Interest: The authors declare no conflict of interest.

\section{References}

1. Hanson, S.; Nicholls, R.; Ranger, N.; Hallegatte, S.; Corfee-Morlot, J.; Herweijer, C.; Chateau, J. A global ranking of port cities with high exposure to climate extremes. Clim. Chang. 2011, 104, 89-111. [CrossRef]

2. Neumann, B.; Vafeidis, A.T.; Zimmermann, J.; Nicholls, R.J. Future coastal population growth and exposure to sea-level rise and coastal flooding-A global assessment. PLoS ONE 2015, 10, e0118571. [CrossRef] [PubMed]

3. Jongman, B.; Ward, P.J.; Aerts, J.C.J.H. Global exposure to river and coastal flooding: Long term trends and changes. Glob. Environ. Chang. 2012, 22, 823-835. [CrossRef]

4. IPCC. Summary for Policymakers. In Climate Change 2013: The Physical Science Basis. Contribution of Working Group I to the Fifth Assessment Report of the Intergovernmental Panel on Climate Change; Stocker, T.F., Qin, D., Plattner, G.-K., Tignor, M., Allen, S.K., Boschung, J., Nauels, A., Xia, Y., Bex, V., Midgley, P.M., Eds.; Cambridge University Press: Cambridge, UK; New York, NY, USA, 2013. 
5. $\quad$ Aerts, J.C.; Lin, N.; Botzen, W.; Emanuel, K.; de Moel, H. Low-probability flood risk modeling for New York City. Risk Anal. 2013, 33, 772-788. [CrossRef]

6. Mori, N.; Kato, M.; Kim, S.; Mase, H.; Shibutani, Y.; Takemi, T.; Tsuboki, K.; Yasuda, T. Local amplification of storm surge by Super Typhoon Haiyan in Leyte Gulf. Geophys. Res. Lett. 2014, 41, 5106-5113. [CrossRef]

7. Pielke, R.A., Jr.; Gratz, J.; Landsea, C.W.; Collins, D.; Saunders, M.A.; Musulin, R. Normalized hurricane damage in the United States: 1900-2005. Nat. Hazards Rev. 2008, 9, 29-42. [CrossRef]

8. IPCC. A Special Report of Working Groups I and II of the Intergovernmental Panel on Climate Change. In Managing the Risks of Extreme Events and Disasters to Advance Climate Change Adaptation; Field, C.B., Barros, V., Stocker, T.F., Qin, D., Dokken, D.J., Ebi, K.L., Mastrandrea, M.D., Mach, K.J., Plattner, G.-K., Allen, S.K., et al., Eds.; Cambridge University Press: Cambridge, UK; New York, NY, USA, 2012; p. 582.

9. Kron, W. Flood Risk = Hazard • Values • Vulnerability. Water Int. 2005, 30, 58-68. [CrossRef]

10. Hallegatte, S.; Green, C.; Nicholls, R.J.; Corfee-Morlot, J. Future flood losses in major coastal cities. Nat. Clim. Chang. 2013, 3, 802-806. [CrossRef]

11. Rahmati, O.; Pourghasemi, H.R.; Zeinivand, H. Flood susceptibility mapping using frequency ratio and weights-of-evidence models in the Golastan Province, Iran. Geocarto Int. 2015, 31, 42-70. [CrossRef]

12. Tehrany, M.S.; Pradhan, B.; Jebur, M.N. Flood susceptibility mapping using a novel ensemble weights-of-evidence and support vector machine models in GIS. J. Hydrol. 2014, 512, 332-343. [CrossRef]

13. Kazakis, N.; Kougias, I.; Patsialis, T. Assessment of flood hazard areas at a regional scale using an index-based approach and Analytical Hierarchy Process: Application in Rhodope-Evros region, Greece. Sci. Total Environ. 2015, 538, 555-563. [CrossRef] [PubMed]

14. Gigović, L.; Pamučar, D.; Bajić, Z.; Drobnjak, S. Application of GIS-Interval Rough AHP Methodology for Flood Hazard Mapping in Urban Areas. Water 2017, 9, 360. [CrossRef]

15. Youssef, A.M.; Pradhan, B.; Sefry, S.A. Flash flood susceptibility assessment in Jeddah city (Kingdom of Saudi Arabia) using bivariate and multivariate statistical models. Environ. Earth Sci. 2015, 75, 12. [CrossRef]

16. Wang, Y.; Hong, H.; Chen, W.; Li, S.; Pamučar, D.; Gigović, L.; Drobnjak, S.; Bui, D.T.; Duan, H. A Hybrid GIS Multi-Criteria Decision-Making Method for Flood Susceptibility Mapping at Shangyou, China. Remote Sens. 2018, 11, 62. [CrossRef]

17. Hong, H.; Tsangaratos, P.; Ilia, I.; Liu, J.; Zhu, A.X.; Chen, W. Application of fuzzy weight of evidence and data mining techniques in construction of flood susceptibility map of Poyang County, China. Sci. Total Environ. 2018, 625, 575-588. [CrossRef] [PubMed]

18. Wang, Y.; Fang, Z.; Hong, H.; Peng, L. Flood susceptibility mapping using convolutional neural network frameworks. J. Hydrol. 2020, 582, 124482. [CrossRef]

19. Tehrany, M.S.; Pradhan, B.; Mansor, S.; Ahmad, N. Flood susceptibility assessment using GIS-based support vector machine model with different kernel types. Catena 2015, 125, 91-101. [CrossRef]

20. Khosravi, K.; Pham, B.T.; Chapi, K.; Shirzadi, A.; Shahabi, H.; Revhaug, I.; Prakash, I.; Bui, D.T. A comparative assessment of decision trees algorithms for flash flood susceptibility modeling at Haraz watershed, northern Iran. Sci. Total Environ. 2018, 627, 744-755. [CrossRef]

21. Chen, W.; Li, Y.; Xue, W.; Shahabi, H.; Li, S.; Hong, H.; Wang, X.; Bian, H.; Zhang, S.; Pradhan, B.; et al. Modeling flood susceptibility using data-driven approaches of naive Bayes tree, alternating decision tree, and random forest methods. Sci. Total Environ. 2020, 701, 134979. [CrossRef]

22. Costache, R.; Hong, H.; Pham, Q.B. Comparative assessment of the flash-flood potential within small mountain catchments using bivariate statistics and their novel hybrid integration with machine learning models. Sci. Total Environ. 2020, 711, 134514. [CrossRef]

23. Mechler, R.; Bouwer, L.M. Understanding trends and projections of disaster losses and climate change: Is vulnerability the missing link? Clim. Chang. 2014, 133, 23-35. [CrossRef]

24. Birkmann, J.; Cardona, O.D.; Carreño, M.L.; Barbat, A.H.; Pelling, M.; Schneiderbauer, S.; Kienberger, S.; Keiler, M.; Alexander, D.; Zeil, P.; et al. Framing vulnerability, risk and societal responses: The MOVE framework. Nat. Hazards 2013, 67, 193-211. [CrossRef]

25. Cutter, S.L.; Boruff, B.J.; Shirley, W.L. Social vulnerability to environmental hazards. Soc. Sci. Q. 2003, 84, 242-261. [CrossRef]

26. Füssel, H.-M.; Klein, R.J. Climate change vulnerability assessments: An evolution of conceptual thinking. Clim. Chang. 2006, 75, 301-329. [CrossRef] 
27. Sterlacchini, S.; Akbas, S.O.; Blahut, J.; Mavrouli, O.-C.; Garcia, C.; Luna, B.Q.; Corominas, J. Methods for the Characterization of the Vulnerability of Elements at Risk. In Mountain Risks: From Prediction to Management and Governance; Springer: Dordrecht, The Netherlands, 2014; pp. 233-273.

28. UNISDR. Global Assessment Report on Disaster Risk Reduction. From Share Risk to Shared Value: The Business Case for Disaster Risk Reduction; United Nations International Strategy for Disaster Reduction Secretariat: Geneva, Switzerland, 2013.

29. Merz, B.; Kreibich, H.; Schwarze, R.; Thieken, A. Review article "Assessment of economic flood damage". Nat. Hazards Earth Syst. Sci. 2010, 10, 1697-1724. [CrossRef]

30. De Moel, H.; Jongman, B.; Kreibich, H.; Merz, B.; Penning-Rowsell, E.; Ward, P.J. Flood risk assessments at different spatial scales. Mitig. Adapt. Strat. Glob. Chang. 2015, 20, 865-890. [CrossRef] [PubMed]

31. Koks, E.E.; Jongman, B.; Husby, T.G.; Botzen, W.J.W. Combining hazard, exposure and social vulnerability to provide lessons for flood risk management. Environ. Sci. Policy 2015, 47, 42-52. [CrossRef]

32. Adger, W.N. Social vulnerability to climate change and extremes in coastal Vietnam. World Dev. 1999, 27, 249-269. [CrossRef]

33. Brooks, N. Vulnerability, risk and adaptation: A conceptual framework. Tyndall Cent. Clim. Chang. Res. Work. Pap. 2003, 38, 1-16.

34. Tapsell, S.; McCarthy, S.; Faulkner, H.; Alexander, M. Social vulnerability to natural hazards. In State of the Art Report from CapHaz-Net's WP4; Middlesex University: London, UK, 2010.

35. Hadipour, V.; Vafaie, F.; Kerle, N. An indicator-based approach to assess social vulnerability of coastal areas to sea-level rise and flooding: A case study of Bandar Abbas city, Iran. Ocean Coast. Manag. 2020, 188, 105077. [CrossRef]

36. Teo, M.; Goonetilleke, A.; Deilami, K.; Ahankoob, A.; Lawie, M. Engaging residents from different ethnic and language backgrounds in disaster preparedness. Int. J. Disaster Risk Reduct. 2019, 39, 101245. [CrossRef]

37. Christie, E.K.; Spencer, T.; Owen, D.; McIvor, A.L.; Möller, I.; Viavattene, C. Regional coastal flood risk assessment for a tidally dominant, natural coastal setting: North Norfolk, southern North Sea. Coast. Eng. 2017, 134, 177-190. [CrossRef]

38. Percival, S.; Teeuw, R. A methodology for urban micro-scale coastal flood vulnerability and risk assessment and mapping. Nat. Hazards 2019, 97, 355-377. [CrossRef]

39. Teo, M.; Goonetilleke, A.; Ahankoob, A.; Deilami, K.; Lawie, M. Disaster awareness and information seeking behaviour among residents from low socio-economic backgrounds. Int. J. Disaster Risk Reduct. 2018, 31, 1121-1131. [CrossRef]

40. Fekete, A. Spatial disaster vulnerability and risk assessments: Challenges in their quality and acceptance. Nat. Hazards 2011, 61, 1161-1178. [CrossRef]

41. Saaty, T.L. The Analytic Hierarchy Process: Planning, Priority Setting, Resources Allocation; McGraw-Hill: New York, NY, USA, 1980; p. 281.

42. Malczewski, J. GIS-based multicriteria decision analysis: A survey of the literature. Int. J. Geogr. Inf. Sci. 2006, 20, 703-726. [CrossRef]

43. Cai, T.; Li, X.; Ding, X.; Wang, J.; Zhan, J. Flood risk assessment based on hydrodynamic model and fuzzy comprehensive evaluation with GIS technique. Int. J. Disaster Risk Reduct. 2019, 35, 101077. [CrossRef]

44. Lin, K.; Chen, H.; Xu, C.-Y.; Yan, P.; Lan, T.; Liu, Z.; Dong, C. Assessment of flash flood risk based on improved analytic hierarchy process method and integrated maximum likelihood clustering algorithm. J. Hydrol. 2020, 584, 124696. [CrossRef]

45. Luu, C.; von Meding, J. A Flood Risk Assessment of Quang Nam, Vietnam Using Spatial Multicriteria Decision Analysis. Water 2018, 10, 461. [CrossRef]

46. Lyu, H.-M.; Shen, S.-L.; Zhou, A.; Yang, J. Perspectives for flood risk assessment and management for mega-city metro system. Tunn. Undergr. Space Technol. 2019, 84, 31-44. [CrossRef]

47. Meyer, V.; Scheuer, S.; Haase, D. A multicriteria approach for flood risk mapping exemplified at the Mulde river, Germany. Nat. Hazards 2008, 48, 17-39. [CrossRef]

48. Ouma, Y.; Tateishi, R. Urban Flood Vulnerability and Risk Mapping Using Integrated Multi-Parametric AHP and GIS: Methodological Overview and Case Study Assessment. Water 2014, 6, 1515-1545. [CrossRef]

49. Wang, Y.; Li, Z.; Tang, Z.; Zeng, G. A GIS-Based Spatial Multi-Criteria Approach for Flood Risk Assessment in the Dongting Lake Region, Hunan, Central China. Water Resour. Manag. 2011, 25, 3465-3484. [CrossRef] 
50. Zhang, D.; Shi, X.; Xu, H.; Jing, Q.; Pan, X.; Liu, T.; Wang, H.; Hou, H. A GIS-based spatial multi-index model for flood risk assessment in the Yangtze River Basin, China. Environ. Impact Assess. Rev. 2020, 83, 106397. [CrossRef]

51. Hsu, T.-W.; Shih, D.-S.; Li, C.-Y.; Lan, Y.-J.; Lin, Y.-C. A Study on Coastal Flooding and Risk Assessment under Climate Change in the Mid-Western Coast of Taiwan. Water 2017, 9, 390. [CrossRef]

52. Li, M.; Wu, W.; Wang, J.; Che, Z.; Xie, Y. Simulating and mapping the risk of surge floods in multiple typhoon scenarios: A case study of Yuhuan County, Zhejiang Province, China. Stoch. Environ. Res. Risk Assess. 2016, 31, 645-659. [CrossRef]

53. Liu, Y.; Lu, C.; Yang, X.; Wang, Z.; Liu, B. Fine-Scale Coastal Storm Surge Disaster Vulnerability and Risk Assessment Model: A Case Study of Laizhou Bay, China. Remote Sens. 2020, 12, 1301. [CrossRef]

54. Cozannet, G.L.; Garcin, M.; Bulteau, T.; Mirgon, C.; Yates, M.L.; Méndez, M.; Baills, A.; Idier, D.; Oliveros, C. An AHP-derived method for mapping the physical vulnerability of coastal areas at regional scales. Nat. Hazards Earth Syst. Sci. 2013, 13, 1209-1227. [CrossRef]

55. ISC. Census Data; Iranian Statistic Center: Tehran, Iran, 2012.

56. Dadras, M.; Shafri, H.Z.; Ahmad, N.; Pradhan, B.; Safarpour, S. Land use/cover change detection and urban sprawl analysis in Bandar Abbas city, Iran. Sci. World J. 2014, 2014, 690872. [CrossRef]

57. Fritz, H.M.; Blount, C.D.; Albusaidi, F.B.; Al-Harthy, A.H.M. Cyclone Gonu storm surge in Oman. Estuar. Coast. Shelf Sci. 2010, 86, 102-106. [CrossRef]

58. IPCC. Climate Change: Impacts, Adaptation, and Vulnerability. Part A: Global and Sectoral Aspects. Contribution of Working Group II to the Fifth Assessment Report of the Intergovernmental Panel on Climate Change; Field, C.B., Barros, V.R., Dokken, D.J., Mach, K.J., Mastrandrea, M.D., Bilir, T.E., Chatterjee, M., Ebi, K.L., Estrada, Y.O., Genova, R.C., et al., Eds.; Cambridge University Press: Cambridge, UK; New York, NY, USA, 2014; p. 1132.

59. Irani, M. Vulnerability Assessment to Seawater Intrusion Coastal Aquifers Affected by Rising Sea Levels Caused by Climate Change (Case Study: Aquifers of Bushehr and Hormozgan Provinces). Master's Thesis, University of Tehran, Tehran, Iran, 2017.

60. Harati, A.N. Decesion Support System in Coastal Inundation under Combined Scenarios. Ph.D. Thesis, K.N.Toosi University of Technology, Tehran, Iran, 2012.

61. Alaska Satellite Facility Distributed Active Archive Data Center. Available online: https://vertex.daac.asf. alaska.edu (accessed on 3 August 2018).

62. Muis, S.; Guneralp, B.; Jongman, B.; Aerts, J.C.; Ward, P.J. Flood risk and adaptation strategies under climate change and urban expansion: A probabilistic analysis using global data. Sci. Total Environ. 2015, 538, 445-457. [CrossRef] [PubMed]

63. Aerts, J.C.; Botzen, W.W.; Emanuel, K.; Lin, N.; De Moel, H.; Michel-Kerjan, E.O. Evaluating flood resilience strategies for coastal megacities. Science 2014, 344, 473-475. [CrossRef] [PubMed]

64. Merz, B.; Thieken, A.H.; Gocht, M. Flood Risk Mapping at the Local Scale: Concepts and Challenges. In Flood Risk Management in Europe; Springer: Dordrecht, The Netherlands, 2007; pp. 231-251.

65. Ahsan, M.N.; Warner, J. The socioeconomic vulnerability index: A pragmatic approach for assessing climate change led risks-A case study in the south-western coastal Bangladesh. Int. J. Disaster Risk Reduct. 2014, 8, 32-49. [CrossRef]

66. Fekete, A. Validation of a social vulnerability index in context to river-floods in Germany. Nat. Hazards Earth Syst. Sci. 2009, 9, 393-403. [CrossRef]

67. Karagiorgos, K.; Thaler, T.; Hübl, J.; Maris, F.; Fuchs, S. Multi-vulnerability analysis for flash flood risk management. Nat. Hazards 2016, 82, 63-87. [CrossRef]

68. Zahran, S.; Brody, S.D.; Peacock, W.G.; Vedlitz, A.; Grover, H. Social vulnerability and the natural and built environment: A model of flood casualties in Texas. Disasters 2008, 32, 537-560. [CrossRef] [PubMed]

69. Foudi, S.; Osés-Eraso, N.; Tamayo, I. Integrated spatial flood risk assessment: The case of Zaragoza. Land Use Policy 2015, 42, 278-292. [CrossRef]

70. De Sherbinin, A.; Bardy, G. Social vulnerability to floods in two coastal megacities: New York City and Mumbai. Vienna Yearb. Popul. Res. 2016, 1, 131-165. [CrossRef]

71. Balica, S.F.; Wright, N.G.; van der Meulen, F. A flood vulnerability index for coastal cities and its use in assessing climate change impacts. Nat. Hazards 2012, 64, 73-105. [CrossRef]

72. Ge, Y.; Dou, W.; Liu, N. Planning Resilient and Sustainable Cities: Identifying and Targeting Social Vulnerability to Climate Change. Sustainability 2017, 9, 1394. [CrossRef] 
73. Yoon, D.K. Assessment of social vulnerability to natural disasters: A comparative study. Nat. Hazards 2012, 63, 823-843. [CrossRef]

74. Cutter, S.L.; Burton, C.G.; Emrich, C.T. Disaster resilience indicators for benchmarking baseline conditions. J. Homel. Secur. Emerg. Manag. 2010, 7, 24. [CrossRef]

75. Kablan, M.K.A.; Dongo, K.; Coulibaly, M. Assessment of Social Vulnerability to Flood in Urban Côte d'Ivoire Using the MOVE Framework. Water 2017, 9, 292. [CrossRef]

76. De Brito, M.M.; Evers, M. Multi-criteria decision-making for flood risk management: A survey of the current state of the art. Nat. Hazards Earth Syst. Sci. 2016, 16, 1019-1033. [CrossRef]

77. Boroushaki, S.; Malczewski, J. Implementing an extension of the analytical hierarchy process using ordered weighted averaging operators with fuzzy quantifiers in ArcGIS. Comput. Geosci. 2008, 34, 399-410. [CrossRef]

78. Deng, H. Multicriteria analysis with fuzzy pairwise comparison. Int. J. Approx. Reason. 1999, 21, $215-231$. [CrossRef]

79. Hadipour, A.; Vafaie, F.; Hadipour, V. Land suitability evaluation for brackish water aquaculture development in coastal area of Hormozgan, Iran. Aquac. Int. 2015, 23, 329-343. [CrossRef]

80. Vafai, F.; Hadipour, V.; Hadipour, A. Determination of shoreline sensitivity to oil spills by use of GIS and fuzzy model. Case study-The coastal areas of Caspian Sea in north of Iran. Ocean Coast. Manag. 2013, 71, 123-130. [CrossRef]

81. Vafaie, F.; Hadipour, A.; Hadipour, V. GIS-based fuzzy multi-criteria decision making model for coastal aquaculture site selection. EEMJ 2015, 14, 11. [CrossRef]

82. Hamidi, A.R.; Wang, J.; Guo, S.; Zeng, Z. Flood vulnerability assessment using MOVE framework: A case study of the northern part of district Peshawar, Pakistan. Nat. Hazards 2020, 101, 385-408. [CrossRef]

83. Kittipongvises, S.; Phetrak, A.; Rattanapun, P.; Brundiers, K.; Buizer, J.L.; Melnick, R. AHP-GIS analysis for flood hazard assessment of the communities nearby the world heritage site on Ayutthaya Island, Thailand. Int. J. Disaster Risk Reduct. 2020, 48, 101612. [CrossRef]

84. Ustaoglu, E.; Aydınoglu, A.C. Suitability evaluation of urban construction land in Pendik district of Istanbul, Turkey. Land Use Policy 2020, 99, 104783. [CrossRef]

85. Perpiña, C.; Martínez-Llario, J.C.; Pérez-Navarro, Á. Multicriteria assessment in GIS environments for siting biomass plants. Land Use Policy 2013, 31, 326-335. [CrossRef]

86. Chen, Y.; Yu, J.; Khan, S. Spatial sensitivity analysis of multi-criteria weights in GIS-based land suitability evaluation. Environ. Model. Softw. 2010, 25, 1582-1591. [CrossRef]

87. Chen, Y.; Liu, R.; Barrett, D.; Gao, L.; Zhou, M.; Renzullo, L.; Emelyanova, I. A spatial assessment framework for evaluating flood risk under extreme climates. Sci. Total Environ. 2015, 538, 512-523. [CrossRef]

88. Highfield, W.E.; Peacock, W.G.; Van Zandt, S. Mitigation Planning. J. Plan. Educ. Res. 2014, 34, $287-300$. [CrossRef]

89. Teo, M.; Lawie, M.; Goonetilleke, A.; Ahankoob, A.; Deilami, K. Engaging vulnerable populations in preparedness and response: A local government context. Aust. J. Emerg. Manag. 2018, 33, 38-47.

90. Tascón-González, L.; Ferrer-Julià, M.; Ruiz, M.; García-Meléndez, E. Social Vulnerability Assessment for Flood Risk Analysis. Water 2020, 12, 558. [CrossRef]

91. Kirby, R.H.; Reams, M.A.; Lam, N.S.N.; Zou, L.; Dekker, G.G.J.; Fundter, D.Q.P. Assessing Social Vulnerability to Flood Hazards in the Dutch Province of Zeeland. Int. J. Disaster Risk Sci. 2019, 10, 233-243. [CrossRef]

(C) 2020 by the authors. Licensee MDPI, Basel, Switzerland. This article is an open access article distributed under the terms and conditions of the Creative Commons Attribution (CC BY) license (http://creativecommons.org/licenses/by/4.0/). 